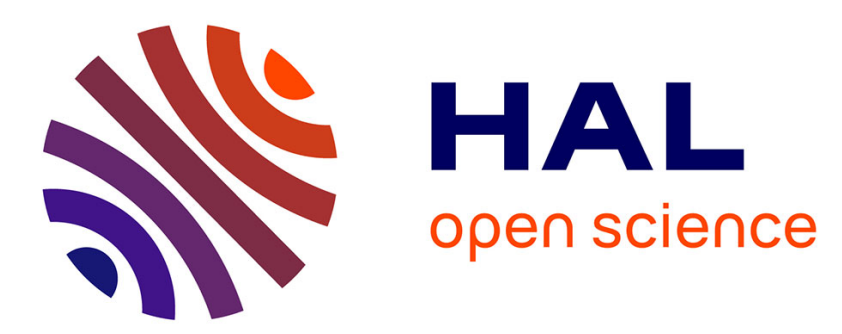

\title{
Stress modulation of the memory retrograde-enhancing effects of the awakening drug modafinil in mice.
}

Daniel Béracochéa, Pierrette Liscia, Christophe Tronche, Frédéric Chauveau, Jean-Claude Jouanin, Christophe Piérard

\section{- To cite this version:}

Daniel Béracochéa, Pierrette Liscia, Christophe Tronche, Frédéric Chauveau, Jean-Claude Jouanin, et al.. Stress modulation of the memory retrograde-enhancing effects of the awakening drug modafinil in mice.. Psychopharmacology, 2008, 196 (1), pp.1-13. 10.1007/s00213-007-0915-8 . hal-00282353

\section{HAL Id: hal-00282353 \\ https://hal.science/hal-00282353}

Submitted on 27 May 2009

HAL is a multi-disciplinary open access archive for the deposit and dissemination of scientific research documents, whether they are published or not. The documents may come from teaching and research institutions in France or abroad, or from public or private research centers.
L'archive ouverte pluridisciplinaire HAL, est destinée au dépôt et à la diffusion de documents scientifiques de niveau recherche, publiés ou non, émanant des établissements d'enseignement et de recherche français ou étrangers, des laboratoires publics ou privés. 
1. Title page

Stress modulation of the memory retrograde enhancing effects of the awakening drug modafinil in mice

Daniel Béracochéa ${ }^{1}{ }$, Pierrette Liscia ${ }^{2}$, Frédéric Chauveau ${ }^{1,2}$, Jean-Claude Jouanin ${ }^{2}$ and Christophe Piérard ${ }^{2}$

1. CNIC (Centre de Neurosciences Intégratives et Cognitives), Universités de Bordeaux 1 et 2, UMR CNRS 5228, avenue des Facultés, 33405 Talence Cedex, FRANCE.

2. IMASSA, Département de Physiologie Intégrée, BP 73, 91223 Brétigny-sur-Orge Cedex, FRANCE

*Author for correspondence: CNIC (Centre de Neurosciences Intégratives et Cognitives), Universités de Bordeaux 1 et 2, UMR CNRS 5228, avenue des Facultés, 33405 Talence Cedex, FRANCE.

Phone: (33) 05-40-00-87-42; Fax: (33) 05-40-00-87-43.

e-mail:d.beracochea@Inc.u-bordeaux1.fr 
$\underline{\text { 2. Abstract and keywords }}$

This study investigated the dose-effect relationship of modafinil administration on contextual memory processes, in parallel with the measurements of plasma corticosterone levels in acutely-stressed mice. Memory was first evaluated in normal (non stressed) mice either in contextual (CSD) or spatial (SSD) tasks. Thus, C57 B1/6 Jico mice learned two consecutive discriminations (D1 and D2) in a four hole-board. The discriminations occured on either distinct (CSD) or identical (SSD) floors (internal contextual cues). All mice received a vehicle i.p. injection before learning, and were injected 24 hours later (twenty minutes prior to the test session) either with vehicle or modafinil. Results showed that modafinil-treated mice behaved similarly as vehicles in the spatial SSD task whereas in contrast, memory of the first-learned discrimination (D1) in the CSD task was enhanced by a $32 \mathrm{mg} / \mathrm{kg}$ but not a $16 \mathrm{mg} / \mathrm{kg}$ modafinil dose. Hence, we studied the effect of a pre-test acute stress (electric footshocks) specifically on D1 performance in modafinil-treated subjects. Immediately after behavioral testing, blood was sampled to measure plasma corticosterone levels. Results showed that : i) stress significantly improved performance in vehicles, ii) stress decreased the efficiency threshold of modafinil, since performance was enhanced at the low dose $(16 \mathrm{mg} / \mathrm{kg})$, whereas this enhancement was obtained for the high dose $(32 \mathrm{mg} / \mathrm{kg})$ in non-stress conditions, iii) the performance was impaired at the high $(32 \mathrm{mg} / \mathrm{kg})$ dose and iv) modafinil significantly reduced the magnitude of the stress-induced corticosterone secretion, mainly at the dose of $32 \mathrm{mg} / \mathrm{kg}$.

Key words: Contextual Memory - Modafinil - Retrieval- Stress - Corticosterone. 
3. Introduction

The issue of drug and stress interconnection with respect to performance, remains a boundless field for research. A wide variety of molecules operates as modulators of neurochemical pathways of vigilance, mainly depending on the interaction between noradrenergic and cholinergic neurons (Buccafusco 2004).

Among them, modafinil or [(diphenylmethyl) sulfinyl]-2 acetamide has been reported as having stimulant and awakening properties without amphetamine-like side effects (Bastuji and Jouvet 1988 ; Hermant et al. 1991 ; Lyons and French 1991). This drug is successfully used in the treatment of narcolepsy and idiopathic hypersomnia without interference however, with nocturnal sleep (Bastuji and Jouvet 1988). Indeed, according to our research, modafinil has been proven to enhance wakefulness by acting on both norepinephrine and dopaminergic systems, through ascending pathways that are likely to promote wakefulness by activating the cortex and other forebrain targets, possibly through interaction with the hypocretin/orexin system (Boutrel and Koob 2004). The mechanism of action of modafinil may also involve a reduction of GABA release in the cerebral cortex (Tanganelli et al. 1992; Piérard et al. 1997) as well as an involvement of excitatory amino acids system (Piérard et al. 1995 ; 1997) and its receptors (Lagarde et al. 1996). Modafinil also enhances energy metabolism, by increasing the energetic pool of phosphocreatine in cortex, thus contributing to vigilance-enhancing properties of this drug (Piérard et al. 1995). In addition, modafinil does not involve the cholinergic system directly in the normal awake rat (Waters et al, 2005). As yet, however, the mechanism of modafinil action is not fully understood. As such, it is still largely surrounded by controversy (Saper and Scammel 2004) and its brain targets remain a matter for debate (Gallopin et al. 2004).

Recent studies have demonstrated that modafinil is able to improve working memory both in animals (Béracochéa et al. 2001) as well as in humans (Muller et al. 
2004); there is further evidence that modafinil enhances learning processes after chronic (Béracochéa et al. 2002) or acute (Béracochéa et al. 2003) systemic administration in mice. These memory-enhancing effects of modafinil (see also Turner et al. 2003), in addition to neuroprotective properties against hypoxia (Lagarde et al. 1993) and organophosphate intoxication (Lallement et al. 1997), could be partly mediated by the involvement of excitatory amino acids neurotransmission systems (Piérard et al. 1997).

In healthy subjects, modafinil is likely to be delivered in stressful conditions (environmental stress, long-term sleep deprivation, or sustained cognitive operations). We recently showed that modafinil is able to restore neural activity and memory performance previously impaired by sleep deprivation in mice (Pierard et al., 2007). Because modafinil was administered after sleep deprivation, this last result evidenced the retrograde effect of modafinil on memory retrieval. It is noteworthy, however, that studies intended to determine the effects of psychostimulant drugs including modafinil on hormone secretions, remain critically scarce (Brun et al. 1998), particularly with reference to stress conditions. Their action might induce an increase in glucocorticoids secretion (cortisol in humans or corticosterone in rodents) through adrenal cortex that could improve psychomotor performance in healthy subjects. Indeed, owing to both fat and protein mobilization, the primary mechanism of glucocorticoid effect is likely to enhance the rate of glucose production in the liver (Shephard 1987) and to increase plasma glucose, as well as glycerol and fatty acids concentrations, in the same manner as epinephrine does (Cerretelli 2002). Moreover, glucocorticoids and their receptors are important mediators of stress response and learning/memory processes (Lupien et al. 1999 ; De Quervain et al. 1998 ; Rozendaal et al. 1996 ; De Kloet 2004 ; Kitraki et al. 2004; Celerier et al., 2004a). 
We hypothesize therefore that glucocorticoids are likely to be involved in the mechanism of modafinil action on memory processes, and that this effect could be modulated under stress conditions. In line with this idea, we already showed that working memory deficits resulting from a chronic stress exposure in mice were alleviated by modafinil and that the memory enhancement in stressed mice was dependent on the interaction between the dose of modafinil and the stress-induced plasma corticosterone level (Pierard et al., 2006).

Hence, the aims of the present study are twofold: in a first step, we investigated the dose-effect relationship of modafinil on the retrieval phase of memory processes (retrograde effects) in non stressed mice submitted to different learning paradigms, involving either internal contextual or external contextual (spatial) cues. Indeed, to our knowledge, the retrograde memory effects of modafinil (and more particularly retrieval memory processes) have never been evaluated in contrast to anterograde memory processes; in a second step, according to the behavioral results obtained, we attempted to determine more specifically the impact of an acute stress on the retrograde memory effects of modafinil in the contextual task, in parallel with the measurement of plasma corticosterone levels. To date, there are no data readily available as regards these important issues with reference to human and /or animal subjects.

\section{$\underline{\text { 4. Materials and methods }}$}

\subsection{Ethical Statement.}

This study was carried out according to the European Convention for the protection of Vertebrate Animals used for Experimental and other Scientific Purposes, and under the agreement \# 94001 delivered by the French Ministry of Defence, after the protocol was examined by the local ethical committee.

\subsection{Animals}


The study was conducted using male mice of the C57 Bl/6 Jico strain obtained at 6 weeks of age from Iffa-Credo, Lyon (France). On arrival, mice were housed collectively in colony cages (40 cm long X $25 \mathrm{~cm}$ high and $20 \mathrm{~cm}$ wide), matched for weight and placed in an animal room (ambient temperature: $22^{\circ} \mathrm{C}$; automatic light cycle: on:7.00 a.m; off:7.00 p.m) with ad lib access to food and water. They remained in collective cages for at least 16 weeks. In all cases, at least 2 weeks before behavioral testing began, mice were housed in individual cages, with ad lib access to food and water. In all experiments, subjects were 24 weeks-old at the time of testing.

\subsection{Apparatus}

All tests were performed in a four-hole board apparatus $(45 \mathrm{~cm} \mathrm{X} 45 \mathrm{~cm}$ X 30 $\mathrm{cm}$ high) enclosed by grey Plexiglass. The four-hole board apparatus was placed on the floor of the room $(3.0 \mathrm{~m} \mathrm{X} 3.0 \mathrm{~m} \mathrm{X} 2.40 \mathrm{~m}$ high). The floor of the board was interchangeable (white and rough; black and smooth). On the floor, 4 holes opening on a food cup (3 cm diameter X $2.5 \mathrm{~cm}$ in depth) were located $6 \mathrm{~cm}$ away from the sidewalls. The apparatus was placed in a room exposed to a $60 \mathrm{~dB}$ background noise and a light centered over the apparatus provided 20 lux intensity at the position of the apparatus. The apparatus was cleaned with $95 \%$ ethanol, then with water before each mouse behavioral testing. Data were automatically monitored by photoelectric cells end video recording. Indeed, photocells placed in each hole were used to measure the following parameters: 1) the number of head-dips in each hole, 2) the duration of headdips in each hole, 3) the total number of head-dips in the 4 holes and 4) the total duration of head-dips in the 4 holes. Thus, in all tasks, the experimenter was outside the behavioral experimental room.

4.4. Procedure.

4.4.1. Habituation. 
Before experiments, mice were handled for 10 min per day over 3 consecutive days before testing began. Mice were submitted to a food deprivation schedule initiated over 4 consecutive days so that, at the time of training, the mice weighed $86-88 \%$ of their initial free-feeding weights. Food ration was adjusted individually in order to maintain the same level of deprivation throughout the ensuing experimental period (acquisition and test sessions).

4.4.2. Experiment 1: Spatial Delayed Discrimination (SD) in a 4-hole-board apparatus.

The behavioral procedure is described in Fig 1, upper part. A session was divided into two phases, the acquisition and the retention ones. The acquisition phase started by placing the subject in a black cylinder $(10 \mathrm{~cm}$ diameter X $20 \mathrm{~cm}$ high) for $30 \mathrm{sec}$, in the center of the hole board. By using this procedure, the subject's initial orientation was made at random. Then, the cylinder was removed, and the mouse was free to explore the hole board for 6 min. During the acquisition phase, which occured in room A (see Fig 1) ten $20 \mathrm{mg}$ food pellets were available in one hole only. The rewarded hole was randomized among subjects. The subject was removed either at the end of the 6 min period, or immediately after the last food pellet had been collected within the 6 min period. Subjects which did not eat all pellets within the 6 min period were discarded from analysis. At the end of the acquisition phase, animals were returned to their home cage and were placed for a two minute period in room B, in order to be consistent with the procedure used in experiment 2. At the end of this two minute period, they were rehoused returned to the animal room for the retention interval. The retention phase was carried out either $30 \mathrm{~min}$ (vehicle only $\mathrm{N}=8$ ) or 24 hours later (vehicle : $\mathrm{N}=8$ and modafinil groups; $16 \mathrm{mg} / \mathrm{kg}=\mathrm{M} 16$, or $32 \mathrm{mg} / \mathrm{kg}=\mathrm{M} 32$ or $64 \mathrm{mg} / \mathrm{kg}=\mathrm{M} 64 ; \mathrm{N}=8$ per 
groups). Mice were injected in room B and remained for $20 \mathrm{~min}$ in this room before being submitted to the test session, which was conducted in room A. During the test session, mice were placed in the hole-board similarly as for the acquisition session, and retention was evaluated by measuring the exploration frequency (number of head dips per hole) for each hole during 6 min. During the test session, food pellets were not placed in the apparatus.

\subsubsection{Experiment 2: Contextual and Serial Discrimination task (CSD)}

The learning of a second discrimination in the CSD task increases the memory load and consequently interference as compared to SD. Interference between serial learnings might result in inapropriate memory recall or accelerated forgetting. Indeed, in our protocol, interference can result from the influence of the acquisition of the first discrimination on retention of the second one (proactive interference) or conversely (retroactive interference). The procedure is described in figure 1.

Acquisition. In room A, mice were first placed at the centre of the board in a PVC tube for 15 seconds and then learned 2 successive spatial discriminations (D1 and D2) for 6 min each. The two serial discriminations differed by the colour and texture (white and smooth versus black and rough) of the floor, and were each separated each by a 2 min time interval during which the mouse was placed in its home cage in room B. For discrimination 1, ten $20 \mathrm{mg}$ pellets were available only in one of the four holes in the board. The baited hole for discrimination 1 was chosen at random. For discrimination 2 , ten $20 \mathrm{mg}$ pellets were systematically located in the diagonally opposite hole. Subjects which did not eat all pellets either at D1 or at D2 within the 6 min period were discarded from analysis. The environmental spatial cues were made of colored and striped papers sheets stuck on the walls of the room, and positioned at 1.00 $\mathrm{m}$ above the floor. These allocentric spatial cues remained at the same place for the two 
successive discriminations. Thus, the discriminations varied only by the internal contextual cues i.e. the different colour and texture of the floor of the four-hole board. Further, the sequencing of the two different floors in the series $\left(1^{\text {st }}\right.$ versus $2^{\text {nd }}$ acquisition) has been systematically alternated from one mouse to another within each group.

Test phase. Retention testing was carried out on independent mice groups for D1 and D2 discriminations and occurred either 30 minutes or 24 hours after the acquisition session. 24 hours after the acquisition phase. Mice were placed either on the floor of discrimination 1 or on the floor of discrimination 2 and were allowed to explore the apparatus freely. Performances were assessed by measuring the exploration for each hole for 6 minutes without any pellets in the apparatus.

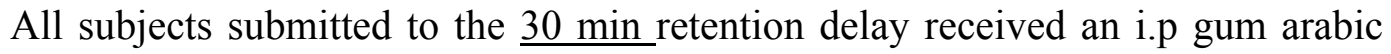
solution (vehicle) twenty minutes before the acquisition session began $(\mathrm{N}=16)$; following the acquisition phase, half of these subjects were tested 30 min later for retention of $\mathrm{D} 1(\mathrm{~N}=8)$ whereas the others were tested for $\mathrm{D} 2(\mathrm{~N}=8)$. All subjects submitted to the 24 hour retention interval $(\mathrm{N}=64)$ received the gum arabic solution as described above before acquisition; 24 hours later, part of these subjects received the gum arabic solution twenty minutes prior to retention testing (controls: $\mathrm{N}=16$ ) whereas the remaining subjects received an i.p.modafinil administration (M16: N=16; M32: $\mathrm{N}=16$; or M64: $\mathrm{N}=16$ ). In both conditions (control and modafinil), half of the subjects were tested for retention of D1 ( $\mathrm{N}=8$ per subgroups) and half were tested for retention of $\mathrm{D} 2$ ( $\mathrm{N}=8$ per subgroups).

The drug injections were given in room B twenty min before memory testing, as in experiment 1 . 
Measurements. This procedure previously described in full in Celerier et al (2004a) allowed us to measure exploration in the "correct" hole (i.e. "correct responses": head-dips into the hole previously baited on the same floor-context during the acquisition phase), the "interfering" response (i.e. head-dips into the hole previously baited on the other floor-context in the acquisition phase) and "errors" (i.e. head-dips into the 2 holes never previously baited during the acquisition phase)

Parameters 1, 2, 3, and 4 allowed calculations of the percentage time spent headdipping ((parameter $2 /$ parameter 4) x 100) as well as percentages of correct or interfering responses ((parameter $1 /$ parameter 3) x 100). Further, the percentage of errors was calculated likewise. Spatial memory was calculated as follows: ((correct responses + interfering responses/ parameter 3) X 100). Spatial responses refer specifically to head-dips made into previously baited holes, regardless of the floor used at the acquisition and retention phases. Thus, within the framework of our analysis, performance depended exclusively on the semantic-like knowledge of external contextual cues associated with food reinforcement at the acquisition phase. Accordingly, spatial memory was an index of the external/semantic contextual memory. Conversely, "correct" responses defined by head-dips into the hole previously baited on the same floor-context during the acquisition phase were stood as an index of the internal/episodic contextual memory.

\subsubsection{Experiment 3: Spatial and Serial Discrimination task (SSD)}

Memory was tested only after a $24 \mathrm{~h}$ retention interval following the acquisition phase. In the acquisition phase, 40 mice were submitted to the very same experimental conditions described in experiment 2 (especially the randomization of the presentation of the $1^{\text {st }}$ floor internal context in the series) except that the same floor (grey color) was used for the two consecutive and diagonally opposite discriminations. 
This procedure allows to reduce the importance of the internal context but increase the importance of external (spatial) cues. Given this procedure, memory of D1 or of D2 is evaluated simultaneously on the same mouse. Subjects which did not eat all pellets within the 6 min period of either one of the two discriminations were discarded from analysis. 24 hours later, a portion of the remaining subjects received the gum arabic solution twenty minutes before retention testing (vehicle: $\mathrm{N}=10$ ) whereas the rest received an i.p.modafinil injection (M16: $\mathrm{N}=10 ; \mathrm{M} 32: \mathrm{N}=10 ; \mathrm{M} 64: \mathrm{N}=10)$. The drug injection was given similarly to the general procedure previously used in experiments 1 and 2. During the retention phase, subjects were re-positioned for $6 \mathrm{~min}$ on the holeboard. This third paradigm (SSD) allowed us to determine the impact of the context change on performance, as compared to the second paradigm (CSD).

Using this procedure, two measures were used: i) \% of correct responses, measured by the number of head-dips in the rewarded holes / by the total number of head-dips X 100; ii) an index of incorrect responses (or "errors"), rated by the total number of head-dips in the two holes never baited during the acquisition sessions / total number of head-dips X 100.

Insert Fig 1 here

For all the above tasks used (SD, CSD , and SSD), the floors of the apparatus were cleaned with $95^{\circ}$ alcohol followed by water in order to remove the olfactive cues from one mouse to another .

\subsection{Modafinil injection}

In all experiments, modafinil (Modiodal $^{\circledR}$, CEPHALON, FRANCE) was suspended in a $0.5 \%$ gum arabic solution used as vehicle and administered 
intraperitoneally $(0.1 \mathrm{ml} / 10 \mathrm{~g}$ of mouse). Behavioral testing started $20 \mathrm{~min}$ after modafinil or vehicle injections.

Subjects submitted to the 30 min retention interval received an i.p. gum arabic injection (used as vehicle) twenty minutes before the acquisition session. Before the test session, the gum arabic or modafinil injections were given in room B. Groups submitted to the 24 hour retention interval received similarly the gum arabic solution before the acquisition session, and received either the gum arabic solution or the modafinil injections 20 minutes before the test session.

\subsection{Acute stress}

Given the overall behavioral results obtained in normal (non stressed) mice, the study of the effects of stress on memory and corticosterone secretion in modafiniltreated subjects were investigated only in subjects submitted to the D1 discrimination of the CSD procedure. The acquisition phase was identical as previously described in non stressed animals, as well as the retention inteval which lasted 24 hours during which animals were relocated in the colony room. During the pre-test treatment period, animals were injected in room B either with modafinil or vehicle solutions; they remained in room $\mathrm{B}$ during $14 \mathrm{~min}$ and were then submitted in room $\mathrm{C}$ to the acute stress treament. Stress treatment was carried out in a stress chamber placed in room C (see Figure 2). The stress chamber $(20 \mathrm{~cm}$ X $15 \mathrm{~cm} \mathrm{X} 15 \mathrm{~cm})$ was enclosed with Plexiglas walls, one transparent and the three others brown. The floor of the conditioning chamber consisted of 35 stainless steel rods ( $3 \mathrm{~mm}$ in diameter), spaced $5 \mathrm{~mm}$ apart and wired to a shock generator for the delivery of three consecutive footshocks $(0.9 \mathrm{~mA} ; 2 \mathrm{sec})$. Mice were placed in the stress chamber for $1 \mathrm{~min}$, and received three consecutive electric footshocks after 10, 30 and $50 \mathrm{sec}$. This procedure 
has been found to increase significantly the HPA axis response to stress (Celerier et al., 2004a). The delivery of these electric footshocks occured 5 min before the test session. The stress chamber was cleaned with $95 \%$ ethanol, then water, after each mouse. Non stressed mice were placed in the same conditions, except that they did not receive any footshock. Following the stress treatment period, animals were housed in room B for 5 min before being submitted to the test phase, during which mice were repositioned on the floor used for the first acquisition (D1). Thus, as in the previous experiments, animals have received either the vehicle solution or the modafinil injections 20 minutes before the test session.

Insert Figure 2 here

\subsection{Corticosterone measurement}

For all the mice groups involved in the study of the effects of stress on CSD performance, behavioral testing as well as blood sampling were performed between 08:30 and 12:00 a.m. Subjects were beheaded $11 \mathrm{~min}$ after acute stress (i.e. immediately at the end of the test session). Mice were decapitated in a separate room in order to avoid the effect of the odor of blood with memory performance of the remaining mice. Then, trunk blood was collected for corticosterone analysis on $50 \mu \mathrm{l}$ plasma samples. The analytical method used was derived from the technique developped by Mason et al. (1992) for rat serum, and validated according to the guidelines of the Association Française de Normalisation (AFNOR guidelines XP T 90210). This modified method was found to be linear on the concentration domain of $[0.025-0.985 \mu \mathrm{g} / \mathrm{ml}]$. Briefly, corticosterone and cortisol (internal standard) were extracted 2 times with ethyl acetate, and acidic hydrolysis $\left(70^{\circ} \mathrm{C}-1\right.$ min) was 
performed in order to create fluorophores. Then, the extract was analyzed by reverse phase HPLC (C18 column) with fluorometric detection $\left(\lambda_{\mathrm{ex}}=375 \mathrm{~nm} ; \lambda_{\mathrm{em}}=485 \mathrm{~nm}\right)$.

\subsection{Statistical analysis}

The data were analysed using one way or two way factorial ANOVAs or ANOVA with repeated measures followed, when adequate by post hoc comparisons (Scheffe's test). Performance comparisons with the chance level were calculated with one sample Student-t-test (chance level $=25 \%$ ). Statistical analyses were performed using the Statview ${ }^{\circledR}$ 5.0.1 software.

\section{Results}

5.1. Effects of modafinil on performance in the SD, CSD and SSD tasks in normal (non stressed) mice.

\section{$\underline{1^{\text {st }} \text { Experiment: Spatial Delayed Discrimination }(\mathrm{SD})}$}

30 min versus 24 hrs. Results are represented in Fig 3A. This analysis was performed using the two independent groups receiving the vehicle solution. The increase of the delay between the learning phase and the test session induced a significant fall of performance. Indeed, the percentage of correct responses was greater at the $30 \mathrm{~min}$ retention interval $(80 \pm 1 \%)$ as compared to the $24 \mathrm{hr}$ retention interval $(63 \pm 4 \% ; \mathrm{F}(1,14)=13.8 ; \mathrm{p}<0.01)$. Conversely, the percentage of incorrect responses was greater at the long retention interval $(36 \pm 4 \%)$ as compared to the short one ( $19 \pm$ $1 \% ; \mathrm{F}(1,14)=13,8 ; \mathrm{p}<0.01)$. The total number of head-dips was similar in both groups $(49,5 \pm 10.1$ and $36,2 \pm 7.8$ for the $30 \mathrm{~min}$ and $24 \mathrm{hrs}$ groups respectively; $F(1,14)<$ $1.0)$.

Modafinil versus Control groups at the 24 hour interval. Results are represented in Fig.3B. Modafinil injections induced no significant changes in the percentage of 
correct responses as compared to the vehicle group (M16: $57 \pm 5 \%$; M32: $71 \pm 2 \%$; M64:63 $\pm 4 \%$; control: $63 \pm 4 \%$; groups: $F(3,28)=1.72 ; \mathrm{p}>0.05)$. Modafinil did not modify the total number of head-dips $(29 \pm 1.7$ versus $36.2 \pm 7.8$ for modafinil and controls respectively; $\mathrm{F}<1.0)$ as well as the number of errors $(\mathrm{F}<1.0)$.

Insert Fig 3 here

$\underline{2^{\text {nd }} \text { Experiment: Contextual Serial Discrimination (CSD) }}$.

30 min versus 24 hrs. Results are represented in Fig 4 A. This analysis was performed using the two independent groups receiving the vehicle solution at the acquisition and retention phases. There proved to be a significant difference between groups evaluated at the short and the long intervals $(F(1,28)=120 ; p=0.0001)$, but performances were not significantly different as a function of the discriminations (D1 vs $\mathrm{D} 2 ; \mathrm{F}(1,28)=3.1 ; \mathrm{p}>0.05) ;$ however, the interaction between groups and discriminations was highly significant $(F(1,28)=8,1 ; \mathrm{p}<0.01)$. As a whole, the percentage of correct responses observed at the short interval was higher as compared to the one observed at the long interval $(F(1,30)=91,8 ; p<0.0001)$. This difference was observed both for D1 (77 $\pm 2 \%$ versus $21 \pm 2 \% ; F(1,14)=190 ; p<0.001)$ and for D2 (72 $\pm 3 \%$ versus $40 \pm 5 \% ; \mathrm{F}(1,14)=21.2 ; \mathrm{p}<0.01)$. Interestingly, performance at $\mathrm{D} 2$ of the 24 hour retention interval $(40 \pm 5 \%)$ were significantly above chance level $(t=-4.31 ; p$ $<0.01)$, as opposed to performance observed at D1 $(21 \pm 2 \% ; \mathrm{t}=1.3 ; \mathrm{p}>0.05)$. The percentage of interfering responses (Fig 4C) in the groups evaluated at the 24 hour retention interval was greater at D1 $(50 \pm 4 \%)$ as compared to $\mathrm{D} 2(22 \pm 2 \% ; \mathrm{F}(1,14)=$ 35.2; $\mathrm{p}<0.0001$ ); this analysis provides evidence to the effect that, in the CSD task, the 
fall of performance at D1 at the $24 \mathrm{hr}$ retention interval is specifically due to retroactive interference.

Modafinil versus Control groups at the 24 hour retention interval. Results are represented in Fig 4B. This analysis was performed using the independent groups receiving either the vehicle solution at acquisition and retention phases (control group) or the vehicle solution at acquisition and modafinil at retention phases (M16, M32 and M64 groups). A global ANOVA showed a significant between groups difference $(\mathrm{F}(3,56)=3.07 ; \mathrm{p}<0.05)$; performance was significantly different as a function of the discrimination (D1 versus D2) $(\mathrm{F}(1,56)=7.5 ; \mathrm{p}<0.01)$ and the interaction between groups and discriminations was also significant $(\mathrm{F}(3,56)=5.4 ; \mathrm{p}<0.01)$. Overall, modafinil subjects exhibited higher performance as compared to controls $(F(1,62)=$ $5.9 ; \mathrm{p}=0.04)$. The enhancing effect of modafinil on performance was mainly observed at D1 $(\mathrm{F}(3,28)=4.3 ; \mathrm{p}<0.01)$; indeed, both the M32 $(45 \pm 8 \%)$ and M64 $(42 \pm 8 \%)$ groups exhibited significant higher performance as compared to controls $(21 \pm 2 \%$; $\mathrm{p}<0.01$ in both comparisons); in contrast, the M16 group exhibited identical performance to those of controls $(22 \pm 2 \% ; \mathrm{F}<1.0)$. Interestingly, the enhancing effect of modafinil was mainly due to a reduction of interfering responses (groups; $F(3,28)=$

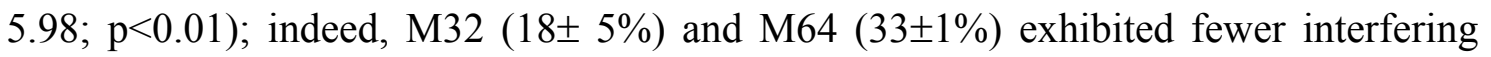
responses as compared either to controls $(50 \pm 4 \%$; $<<0.05$ in both comparisons) or to M16 (51 \pm 3\%; $<0.05$ in both comparisons) (see Fig.3C). Incorrect choices were not statistically different among the groups $(\mathrm{F}(3,28)<1.0)$.

Retention of D2 was also modified by modafinil injection (groups; $F(3,28)=4.2$; $\mathrm{p}<0.01)$. More precisely, the inter-group difference was mainly due to the M64 group which exhibited significant lower performance $(31 \pm 5 \%)$ as compared to controls $(40 \pm$ $5 \% ; \mathrm{p}<0.05)$ and as compared to M16 (54 $\pm 5 \%)$ and M32 (50 $\pm 2 \%)$ groups $(\mathrm{p}<0.02$ in 
all comparisons). Nevertheless, after accouting for errors, the significance between the M64 and control groups can be considered as a borderline effect. No significant difference was observed between the M32, M16 and controls ( $>0.05$ in all comparisons). Interestingly, the fall of performance in the M64 group was not due to a higher number of interfering responses (M64:18 $\pm 6 \%$, versus $19 \pm 3 \%, 30 \pm 4 \%$ and 21 $\pm 3 \%$ for the M16, M32 and controls respectively; F $<1.0$ in all comparisons). The M64 group exhibited also a higher number of incorrect choices $(50 \pm 6 \%)$ as compared to the M16 $(25 \pm 4 \% ; \mathrm{F}(1,14)=10.3 ; \mathrm{p}<0.01)$ and the $\mathrm{M} 32(19 \pm 1 \% ; \mathrm{F}(1,14)=24.8 ; \mathrm{p}<0.01)$ groups; however, the number of incorrect choices of the M64 group was not statistically different from that of controls $(38 \pm 8 \% ; \mathrm{F}(1,14)=1.26 ; \mathrm{p}>0.05)$.

Insert Fig 4 here

The mean number of head-dips (D1+D2) was not significantly modified by modafinil $(49.2 \pm 4.1)$ as compared to controls $(57.5 \pm 7.8 ; \mathrm{F}<1.0)$.

$3^{\text {rd }}$ experiment. Spatial Serial Discrimination (SSD).

Results are represented in Fig 5. Repeated measures ANOVA showed that performance assessed by the percentage of correct choices was significantly different as a function of the discrimination (D1 versus D2) $(\mathrm{F}(1,37)=4.8 ; \mathrm{p}<0.05)$ but the interaction between groups was not significant $(F(3,37)=0.24)$ and the interaction between groups and discriminations was also not significant $(F(3,37)<1.0)$. More specifically, all groups responded at chance and exhibited similar levels of performance at D1 $(24 \pm 7 \%, 29 \pm 5 \%, 23 \pm 3 \%$ and $25 \pm 5 \%$ for respectively control, M16, M32 
and M64 groups; $\mathrm{F}<1.0$ in all comparisons); in contrast, all groups exhibited performance significantly above chance level ( $\mathrm{p}<0.03$ in all comparisons) at D2 but no statistical difference was observed among the groups $(39 \pm 8 \%, 39 \pm 6 \%, 38 \pm 7 \%$ and $37 \pm 3 \%$ for control, M16, M32 and M64 groups respectively; $\mathrm{F}<1.0$ in all comparisons).

Insert Fig 5 here

The mean number of head-dips was not significantly modified by modafinil $(32.2 \pm 3.1)$ as compared to controls $(28.4 \pm 4.2 ; \mathrm{F}<1.0)$.

5.2. Effects of stress on the modafinil-induced dose-dependent enhancement of D1 performance in the CSD task and on corticosterone secretion.

In so far as the main enhancing effect of modafinil was observed on D1 performance of the CSD task, we investigated the effects of stress in this specific D1 situation. In stressed and non stressed conditions, mice have been submitted to behavioral testing, whereas subjects of the quiet condition remained in the colony room and did not experience behavioral testing. Animals submitted to behavioral testing were submitted to the acquisition phase (learning of D1 and D2) as previously described, whereas memory testing was made by repositioning the subject on the floor used for the D1 discrimination only.

Stressed M16 $(\mathrm{N}=8)$, stressed M32 $(\mathrm{N}=8)$ and stressed vehicle $(\mathrm{N}=8)$ groups were compared to non stressed M16 $(\mathrm{N}=8), \mathrm{M} 32(\mathrm{~N}=8)$ and vehicle $(\mathrm{N}=8)$ groups in the behavioral task. In addition, for the purposes of corticosterone analysis, the level of plasma corticosterone was also evaluated in quiet subjects remaining in the colony 
room, and receiving either the M16 or the M32 doses or vehicle (N=3 in each group) 26 min before sacrifice, in order to be consistent with animals submitted to behavioral testing.

The overall results are summarized in Figure 6.

The analysis performed on correct response rates (Fig 6A) showed a non significant difference between treatments (M16, M32 and vehicle; F $(2,42)=1.3$; $\mathrm{p}>0.05$ ), but a significant difference between conditions (stress versus no stress; $F(1,42)=10.9 ; p<0.01)$. Further, the interaction between treatments and conditions was highly significant $(\mathrm{F}(2,42)=16.0 ; \mathrm{p}<0.0001)$. More specifically, stress induced a significant enhancement of performance in the M16 (52 $\pm 3 \%)$ and vehicle (45 $\pm 3 \%)$ groups, as compared to their respective non stressed condition (M16: $24.4 \pm 1.7 \%$; control: $31 \pm 4 \% ; p<0.001$ and $p<0.05$ respectively for M16 and vehicle). In contrast, the opposite effect was observed in M32 mice which exhibited higher performance in the non stressed condition $(50.0 \pm 1.4 \%)$ as compared to the stressed one $(36.7 \pm 5 \%$; $F(1,14)=6.5 ; p<0.05)$

Interestingly, the enhancing effect of modafinil at $16 \mathrm{mg} / \mathrm{kg}$ in stressed mice was due to a dramatic reduction of interfering responses (Fig 6B; stressed M16: $23.4 \pm$ 1.7\% versus non stressed M16: $51.7 \pm 3 \% ; \mathrm{F}(1,14)=52.5 ; \mathrm{p}<0.0001)$, a phenomenon which was also encountered in vehicle-treated mice even though the difference was not statistically significant (stressed: $35.6 \pm 4 \%$ versus non stressed: $45.4 \pm 5 \% ; F(1,14)=$ $1.85 ; \mathrm{p}>0.05)$. The opposite effect was observed in M32 mice which exhibited a higher level of interfering responses in the stress condition (36.6 $4 \%$ ) as compared to the non stress one $(29.9 \pm 1.8 \%)$, even though this difference was not statistically significant $(p>0.20)$. Spatial responses were substantial (above 70\%) in all groups and did not significantly differed among the groups $(F(2,42)=0.28)$ nor conditions (stress versus 
non stress; $F(1,42)<1.0)$, the interaction between groups and conditions being also not statistically significant $(\mathrm{F}(2,42)=0.18 ; \mathrm{p}>0.05)$.

Plasma corticosterone levels: ANOVA on corticosterone concentrations performed in quiet subjects did not reveal any significant difference among the groups $(p>0.20)$. Analysis performed in non stressed mice showed that behavioral testing significantly increased plasma corticosterone levels as compared to the quiet condition $(\mathrm{F}(1,27)=16.1 ; \mathrm{p}<0.0001)$. Comparisons between stressed and non stressed mice showed a non significant difference among the groups (vehicle, M16 and M32 mice; $F(2,42)=1.0 ; p>0.05$ ), a significant difference between conditions (stress versus no stress; $F(1,42)=5.9 ; p<0.05)$ whereas the interaction between groups and conditions was not significant $(F(2,42)<1.0)$. As a whole, modafinil did not significantly modify the levels of corticosterone in the non stress condition as compared to vehicle-treated mice (M16: 0.04 $\pm 0.01 \mu \mathrm{g} / \mathrm{ml} ; \mathrm{M} 32: 0.05 \pm 0.009 \mu \mathrm{g} / \mathrm{ml}$; vehicle: $0.05 \pm 0.01 \mu \mathrm{g} / \mathrm{ml}$; $\mathrm{F}(2,21)<1.0)$ as well as in the stress one $(\mathrm{M} 16: 0.07 \pm 0.008 \mu \mathrm{g} / \mathrm{ml} ; \mathrm{M} 32: 0.06 \pm$ $0.008 \mu \mathrm{g} / \mathrm{ml}$; vehicle: $0.12 \pm 0.04 \mu \mathrm{g} / \mathrm{ml} ; \mathrm{F}(2,21)=1.2 ; \mathrm{p}>0.05)$.

Intra-group analysis revealed that the plasma corticosterone level is statistically significant in vehicle-treated animals in the stress condition, as compared to the non stress one $(\mathrm{F}(1,14)=6.2 ; \mathrm{p}<0.05)$ whereas differences failed to reach the statistical level of significance in the two modafinil groups ( $p>0.10$ in each comparisons, as compared to their respective non stressed group). Hence, we may hypothesize that modafinil reduced the magnitude of the stress-induced corticosterone increase, as compared to vehicle-treated mice. In order to assess our hypothesis, we studied the magnitude of the stress-induced corticosterone secretion. The magnitude of the corticosterone increase under stress was calculated by the following ratio: (individual corticosterone scores in the stress condition / mean corticosterone score of the respective non stressed group); in this analysis, a ratio of " 1.0 " means that stressed 
mice exhibit a level of corticosterone equal to the one observed in the non stress condition.

This analysis revealed a significant between group difference $(\mathrm{F}(2,21)=6.9$; $\mathrm{p}<0.01)$. More specifically, the M32 group exhibited a significant lower ratio (1.23 $\pm 1,7)$ as compared to the M16 group (1.78 $\pm 2.0 ; \mathrm{p}<0.02)$ and vehicle-treated mice $(2.0$ $\pm 1.47 ; \mathrm{p}<0.01)$.

\section{Insert Figure 6 here}

\section{Discussion}

The main results of the study are as follow: 1) the SSD and the CSD tasks involved greater memory load as compared to the SD task; indeed, choice accuracy in controls is greater in the SD task as compared to D1 and D2 scores of both the SSD and the CSD ones. In the CSD task, choice accuracy for both D1 and D2 is greater at the short retention interval (30 $\mathrm{min})$ as compared to the long one (24hrs) ; interestingly, control subjects exhibited similar retrieval curves both in the SSD and the CSD tasks, retrieval of D2 being greater than retrieval of D1;2) at the $24 \mathrm{hr}$ retention interval, modafinil did not induce significant memory effects in both SD and SSD tasks; in contrast, modafinil induced a dose-dependent modulation of performance in the CSD task, which involved distinct internal contextual cues between discriminations during the acquisition phase. The M32 dose induced the greater enhancing memory effect as compared to the M16 (no significant effect on D1 and on D2) and the M64 doses (significant enhancement of D1 and significant impairment of D2) ; 3) Stress induced a significant enhancement of performance in the M16 and control groups as compared to non stressed M16 and control mice; in contrast, stressed M32 mice showed an opposite 
pattern of performance, since stressed M32 mice were significantly impaired as compared to non stressed M32 mice; 4) stress induced a significant increase of plasmatic corticosterone level in control mice as compared to the non stress condition; in addition, the stress-induced activation of plasmatic corticosterone levels was substantially reduced in M32 mice.

Memory effects of modafinil in non stressed mice.

As shown in the CSD task, M32 and M64 but not M16 doses improved the retrieval of discrimination 1, as compared to controls. Interestingly, this improvement was specifically due to a reduction of retroactive interference in so far as the number of interfering responses was significantly lower as compared to controls. In contrast, the number of errors (visits of the holes not previously baited in the acquisition phase) was not altered by modafinil injection. As opposed to the M32 dose, the M64 dose generated a parallel but borderline impairment of the retrieval of D2, which was due to an increased number of errors. Overall, the M32 dose emerged as having the more powerful enhancing memory effect since memory of D1 is enhanced, whereas in parallel, the retrieval of D2 was spared.

Interestingly, the memory retrieval-enhancing effect of modafinil at the M32 dose was not observed when the acquisition of the two successive discriminations (D1 and D2) took place in the same floor context, which indicates that the promnesiant effect of modafinil is dependent on the internal context. Thus, in non stressed animals, modafinil, --mainly at the $32 \mathrm{mg} / \mathrm{kg}$ dose--, enhanced the use of internal contextual cues at the time of retrieval.

\section{Memory effects of modafinil on stressed mice}

First of all, in our experimental conditions, both behavioral testing and blood sampling were carried out between 8.30 am and 12.00 am., i.e. several hours before the 
onset of the plasma corticosterone peak, while its level remained low and stable. Indeed, the peak of plasma corticosterone occurred 2 hours before the beginning of the activity phase (Halberg et al., 1959), i.e. at about 5.00 pm., because light was turned off at $7.00 \mathrm{pm}$. in our animal room. Thus, we may assume that circadian influence on corticosterone level and behavior did not interfere with the interpretation of our results.

Interestingly, the acute stress enhanced performance of both control and M16 groups as compared to the non stress condition, while inducing the opposite effect in M32-treated mice. The enhancement of performance in stressed M16 and stressed control animals was specifically due to a reduction of interfering responses. From the present overall behavioral data, we may draw the following conclusion, namely: acute stress enhanced contextual memory in controls as opposed to non stressed mice; concomitantly, acute stress decreased the efficiency threshold of modafinil since the dose required to observe an enhancing effect on performance is lower in the stress condition as compared to the non stress one (M16 versus M32 respectively). The latter result coincides with our previous work in chronically-stressed mice (Piérard et al., 2006). Moreover, stress also lowered the detrimental threshold of modafinil since the M32 dose disrupted D1 performance in stressed mice. Thus, our present study clearly demonstrates that an acute stress modulates the dose-dependent effects of modafinil on memory.

\section{Effect of modafinil on corticosterone secretion}

In the present study, we found that modafinil i) did not modify the basal corticosterone level (quiet condition) as compared to vehicle, and ii) as a function of the dose, modafinil reduced the magnitude of the stress-induced corticosterone secretion as regards the non stress condition. This result corroborates our previous study in chronically stressed mice, where modafinil suppressed the stress-induced increase in 
corticosterone secretion observed in control mice (Piérard et al., 2006). Thus, on the one hand, only stressed controls significantly differed from the non stress condition; on the other hand, the magnitude of the stress-induced increase of corticosterone was significantly reduced in the M32 group, as compared to both placebo and M16 mice. Furthermore, our study demonstrates that modafinil lowered the hypothalamohypophyso-adrenal response to an acute stress as regards to the non-stress condition. Nevertheless, our study did not prove that the modafinil-induced corticosterone changes are directly involved in memory performance. On the one hand, the two groups (placebo and M16) exhibiting the greatest stress-induced corticosterone activation also exhibited an enhancement of D1 performance, as compared to their respective nonstress condition ; on the other hand, the M32 group showed the inverse pattern: non stressed mice exhibited both a lower corticosterone level and higher memory scores, as compared to stressed subjects.

\section{Behavioural effects of modafinil in rodents tasks.}

In contrast to the numerous studies concerning the stimulant locomotor effects of modafinil (see Simon et al., 1996) and its well-known awakening properties, the effects of modafinil on cognitive processes are less investigated in rodents.

In particular, the study of the retrograde memory effects of modafinil has been only scarcely studied in contrast to the reference awakening drug, amphetamine. Indeed, in rodents, amphetamine facilitates memory retrieval (Sara and Deweer, 1982 ; Altman and Quartermain, 1983 ; Millin and Riccio, 2004) by activating a non-specific general retrieval system, and alleviates forgetting caused by diverse pathophysiological and pharmacological factors (Quatermain et al., 1988 ; Quatermain and Jung, 1989). However, some human studies show that the amphetamine-induced facilitation of memory tasks, involves consolidation phase (Soetens et al., 1993), but is independent of 
retrieval (Zeews and Soetens, 2007). Besides the awakening drugs amphetamine and modafinil, other molecules such as opioid ligands (Ilyutchenok and Dubrovina, 1995) and glucose (Sünram-Lea et al., 2002) can enhance memory retrieval. On the contrary, memory retrieval can be impaired by anticholinergic drugs such as atropine (Boccia et al., 2003) or high circulating levels of glucocorticoids (Roozendaal, 2002).

To the best of our knowledge, only our previous study has already shown that modafinil induced a retrograde memory-enhancing effect (Beracochea et al., 2003 ; Piérard et al., 2007). More specifically, it was found that modafinil induced a faster emergence of a learning set rule, according to the amount of training ( 1 day or 4 days) occurring prior the injection. Thus, the present study shows that the enhancement of retrograde memory of modafinil is also observed on episodic-like memory. Nevertheless, one could hypothetized that the effects of modafinil on retrieval processes might be due to an increase of attentional processes as demonstrated in human studies (Turner et al., 2003; Ballon and Feifel, 2006) but such an effect has not been evidenced in the normal awake rat (Waters et al. 2005).

The glucocorticoids could be involved in the behavioural effects of modafinil under stress conditions in relation with the dopaminergic system. Indeed, it has been evidenced a coordinate action of glucocorticoids and psychostimulant drugs on dopaminergic neurotransmission (De Jong and De Kloet, 2004). More precisely, corticosterone regulates dopamine D-1 receptors, that could in turn regulate the release of corticosterone by activation of neurons in the paraventricular nucleus ot hypothalamus (Czyrak et al., 2003), that is a main brain target of psychostimulant drugs not only modafinil but also amphetamine (Engber et al., 1998). Furthermore, from a behavioural point of view, Mizoguchi et al. (2004) have shown that the suppression of glucocorticoids through a D1 receptor mediated mechanism in the prefrontal cortex could impair memory processes. In contrast, it has been suggested that the action of 
modafinil does not involve directly the cholinergic neurotransmission in rats (Waters et al., 2005).

Conclusion.

Overall, the goal of our study has been to demonstrate all at once i) an enhancement of the serial contextually-based retrieval memory processes following modafinil administration in non stressed mice ; ii) a modulation of the dose-effects of modafinil on memory performance under stress condition; iii) an interaction betwen modafinil and glucocorticoids secretion in acutely stressed mice even though the relationships between glucocorticoids secretion and memory performance remain under questions in modafinil-treated animals.

Acknowledgements:

The authors are grateful to Frances Ash (ashberac@free.fr) for language assistance, and to Dominique Bonneau and Bruno Huart for their analytical expertise for corticosterone dosages.

This research was supported by a grant (Opération $n^{\circ}$ 03co015-05 - PEA 010801) from Délégation Générale pour l'Armement (DGA/DET/SCET/CEP/SHP, Paris, France) and by the CNRS.

7. References 
Altman ,HJ, Quartermain, D (1983) facilitation of memory retrieval by centrally administered catecholamine stimulating agents. Behav. Brain Res. 7: 51-63.

Bastuji, H, Jouvet, M. (1988). Successful treatment of idiopathic hypersomnia and narcolepsy with modafinil. Prog. Neuropsychopharmacol. Biol. Psychiat. 12: 695700 .

Ballon, JS, Feifel, D. (2006) Systematic review of modafinil: potential clinical uses and mechanisms of action. J.Clin . Psychiatry 67: 554-566.

Béracochéa, D, Cagnard, B, Célérier, A, Le Merrer, J, Pérès, M, Piérard, C (2001). First evidence of a delay-dependant working memory-enhancing effect of modafinil in mice. Neuroreport 12:375-378.

Béracochéa, D, Célérier, A, Borde, N, Valleau, M, Pérès, M, Piérard, C (2002). Improvement of learning processes following chronic systemic administration of modafinil in mice. Pharmacol. Biochem. Behav. 73:723-728.

Béracochéa, D, Célérier, A, Pérès, M, Piérard, C (2003 ). Enhancement of learning processes following an acute modafinil injection in mice. Pharmacol. Biochem. Behav. 76:473-479.

Beracochea, D., Célérier, A., Pierard, C (2004). The $\beta$-CCM but not physostigmine enhancement of memory retrieval depends on emotional processes in mice. Psychopharmacology. 176 : 66-73.

Boccia, MM, Blake, MG, Acosta, GB, Baratti, CM (2003). Atropine, an anticholinergic drug, impairs memory retrieval of a high consolidated avoidance response in mice. Neurosci. Lett. 345: 97-100.

Boutrel, B, Koob, GF (2004). What keeps us awake : the neuropharmacology of stimulants and wakefulness-promoting medications. Sleep 27:1181-1194.

Brun, J, Chamba, G, Khalfallah, Y, Girard, P, Boissy, I, Bastuji, H, Sassolas, G, Claustrat, B (1998). Effects of modafinil on plasma melatonin, cortisol and growth 
hormone rhythms, rectal temperature and performance in healthy subjects during a 36-h sleep deprivation. J. Sleep Res. 7:105-114.

Buccafusco JJ. Cognitive enhancing drugs. Basel : Birkhäuser Verlag, 2004.

Célérier, A, Piérard, C, Rachbauer, D, Sarrieau, A, Béracochéa, D (2004a). Contextual and serial discriminations : a new learning paradigm to assess simultaneously the effects of acute stress on retrieval of flexible or stable information in mice. Learning and Memory . 11:196-204.

Celerier, A., Pierard, C., Beracochea, D.(2004b) Beta-CCM enhances retrieval of serial contextual but not of serial spatial memory in mice. Behavioral Pharmacology. 15: $123-131$.

Cerretelli P. Interventions à caractère pharmacologique sur la capacité de prestation athlétique. In : Traité de physiologie de l'exercice et du sport. Paris : Masson, 2002, p 284.

Czyrak A, Mackowiak M, Chocyk A, Fijal K, Wedzony K (2003). Role of glucocorticoids in the regulation of dopaminergic neurotransmission. Pol. J. Pharmacol. 55:667-674.

De Jong IE, De Kloet ER (2004). Glucocorticoids and vulnerability to psychostimulant drugs : toward substrate and mechanism. ANN. NY Acad. Sci. 1018:192-198.

De Kloet, ER (2004). Hormones and the stressed brain. Ann. NY Acad. Sci. 1018:1-15.

De Quervain, DJF, Roozendaal, B, McGaugh, JL (1998). Stress and glucocorticoids impair retrieval of long-term spatial memory. Nature. 394:787-790.

Engber, TM, Koury, EJ, Dennis, SH, Miller, MS, Contreras, PC, Bhat, RV (1998). Differential patterns of regional c-Fos induction in the rat brain by amphetamine and the novel wakefulness-promoting agent modafinil. Neurosci. Lett. 241:95-98. 
Gallopin, T, Luppi, PH, Rambert, FA, Frydman, A, Fort, P (2004). Effect of the wakepromoting agent modafinil on sleep-promoting neurons from the ventrolateral preoptic nucleus : an in vivo pharmacologic study. Sleep . 27:19-25.

Halberg, F, Albrecht, PG, Bittner, JJ (1959). Corticosterone rhythm of mouse adrenal in relation to serum corticosterone and sampling. Am. J. Physiol. 197:1083-1085.

Hermant, JF, Rambert, F, Duteil, J (1991). Awakening properties of modafinil : effect of nocturnal activity in monkeys (Macaca mulatta) after acute and repeated administration. Psychopharmacol. 103:28-32.

Ilyutchenok, RY, Dubrovina, NI (1995). Memory retrieval enhancement by kappa opioid agonist and mu, delta antagonists. Pharmacol. Biochem. Behav. 52: 683-687.

Kitraki, E, Kremmyda, O, Youlatos, D, Alexis, M, Kittas, C (2004). Spatial performance and corticosteroid receptor status in the 21-day restraint stress paradigm. Ann. NY Acad. Sci. 1018: 323-327.

Lagarde, D, Trocherie, S, Morlet, T, Mothet, JP, Van Beers, P (1993). Evaluation of the effects of modafinil in hypobaric hypoxia in Rhesus monkeys. Med. Sci. Res. 21:633-636.

Lagarde, D, Batejat, D (1995). Disrupted sleep-wake rhythm and performance : advantages of modafinil. Milit. Psychol. 7:165-191.

Lagarde, D, Batejat, D, Van Beers, P, Sarafian, D, Pradella, S (1996). Interest of modafinil, a new psychostimulant, during a sixty-hour deprivation experiment. Fundam. Clin. Pharmacol. 9:271-279.

Lallement, G, Piérard, C, Masqueliez, C, Baubichon, D, Pernot-Marino, I, Pérès, M, Lagarde, D (1997). Neuroprotective effect of modafinil against soman-induced hippocampal lesions. Med. Sci. Res. 25:437-440. 
Lupien, SJ, Gillin, CJ, Hauger, RL (1999). Working memory is more sensitive than declarative memory to the acute effects of corticosteroids: a dose-response study in humans. Behav. Neurosci. 113:420-430.

Lyons, TJ, French, J (1991). Modafinil : the unique properties of a new stimulant. Aviat. Space Environ. Med. 62:432-435.

Marinelli, M, Piazza, PV (2002). Interaction between glucocorticoid hormones, stress and psychostimulant drugs. Eur. J. Neurosci. 16:387-394.

Mason, SR, Ward, LC, Reilly, PE (1992). Fluorometric detection of serum corticosterone using high-performance chromatography. J. Chromatogr. 581:267271.

Millin PM, Riccio DC. (2004) Is the context shift effect a case of retrieval failure? The effects of retrieval enhancing treatments on forgetting under altered stimulus conditions in rats. J Exp. Psychol. Anim. Behav. Process. 30: 325-334.

Mizoguchi K, Ishige, A, Takeda, S, Aburada M, Tabira, T (2004). Endogenous glucocorticoids are essential for maintaining prefrontal cortical cognitive function. J. Neurosci. 24: 5492-5499.

Muller, U, Steffenhagen, N, Regenthal, R, Bublak, P (2004). Effects of modafinil on working memory processes in humans. Psychopharmacol. 177:161-169.

Piérard, C, Satabin, P, Lagarde, D, Barrère, B, Guezennec, CY, Menu, JP, Pérès, M (1995). Effects of a vigilance-enhancing drug, modafinil, on rat brain metabolism : a 2D ${ }^{1}$ H-NMR study. Brain Res. 693:251-256.

Piérard, C, Lagarde, D, Barrère, B, Duret, P, Cordeiro, C, Guezennec, CY, Pérès, M (1997). Effects of a vigilance enhancing-drug, modafinil, on rat brain cortex amino acids : a microdialysis study. Med. Sci. Res. 25:51-54. 
Piérard C, Liscia P, Valleau M, Drouet I, Chauveau F, Huart B, et al (2006). Modafinil-induced modulation of working memory and plasma corticosterone in chronically-stressed mice. Pharmacol.Biochem.Behavior. 83:1-8.

Pierard,C , Liscia, P, Phillipin, JN, Mons,N, et al. (2007) Modafinil restore memory performance and neural activity impaired by sleep deprivation in mice. Pharmacol.Biochem. Behav., in press.

Quartermain, D, Judge, ME, Jung, H. (1988). Amphetamine enhances retrieval following diverse sources of forgetting. Physiol Behav. 43: 239-241.

Quatermain, D, Jung, H (1989). Persistence of retrieval enhancement by amphetamine following scopolamine-induced amnesia. Pharmacol. Biochem. Behav. 33: 51-54.

Roozendaal, B, Bohus, B, McGaugh, JL (1996). Dose-dependent suppression of adrenocortical activity with metyrapone: effects on emotion and memory. Psychoneuroendocrinology. 21:681-693.

Roozendaal, B (2002). Stress and memory: opposing effects of glucocorticoids on memory consolidation and memory retrieval. Neurobiol. Learn. Mem. ; 78:578-595.

Saper, CB, Scammel, TE (2004). Modafinil : a drug in search of a mechanism. Sleep. 27:19-25.

Sara, SJ, Deweer, B (1982). Memory retrieval enhanced by amphetamine after a long retention interval. Behav. Neural Biol. 36: 146-160.

Sauro, MD, Jorgensen, RS, Pedlow, CT (2003). Stress, glucocorticoids, and memory : a meta-analytic review. Stress . 6:235-245.

Shephard RJ. Exercise physiology. Toronto, Philadelphia : BC Decker Inc, 1987 ; p 41.

Simon P, Hemet, C, Constantin, J, (1996) Analyses of stimulant locomotor effects of modafinil in various strains of mice and rats. Fundam.Clin.Pharmacol. 10:431-435. 
Sünram-Lea, SI, Foster, JK, Durlach, P, Perez, C (2002). The effect of retrograde and anterograde glucose administration on memory performance in healthy young adults. Behav. Brain Res. 134: 505-516.

Tanganelli, S, Fuxe, K, Ferraro, L, Janson, AM, Bianchi, C (1992). Inhibitory effects of the psychoactive drug modafinil on gamma-aminobutyric acid outflow from the cerebral cortex of the awake freely moving guinea-pig. Possible involvement of 5hydroxytryptamine mechanisms. Naunyn Schmiedebergs Arch. Pharmacol. 345:461-465.

Turner, DC, Robbins, TW, Clark, L, Aron, AR, Dowson, J, Sahakian, BJ (2003). Cognitive enhancing effects of modafinil in healthy volunteers. Psychopharmacol. 165: $260-269$.

Waters, KA, Burnham, KE, O4Connor, D, Dawson, GR, Dias, R. (2005) Assessment of modafinil on attentional processes in a five-choice serial reaction time test in the rats. J Psychopharmacol. 19: 149-158.

Zeeuws, I, Soetens, E (2007). Verbal memory performance improved via an acute administration of D-amphetamine. Hum. Psychopharmacol. 22: 279-287. 
9. Figures.

Fig.1: Behavioral procedures of the 3 experimental tasks: Spatial Delayed Discrimination, SD (up); Contextual and Serial Discriminations, CSD (middle) and Spatial and Serial discriminations, SSD (bottom). Room A and room B were different, but the same rooms and apparatus were used in the three tasks.

Fig. 2: Behavioral procedure used to evaluate the effects of stress on memory performance of the D1 discrimination in modafinil-treated subjects.

Fig. 3: A: Effects of the lengths of the retention interval on SD performance of vehicle-treated mice. Comparisons between $30 \mathrm{~min}$ and 24 hours ; **: p<0.01; B: Effects of modafinil on SD performance at the 24 hours retention interval. No between groups difference was observed.

Fig.4: A: Effects of the lengths of the retention interval on CSD performance (correct responses) in vehicle-treated mice. ${ }^{* *}: \mathrm{p}<0.001$ between the two groups at each delay interval; B: Effects of modafinil on CSD performance (correct responses) at the 24 hours retention interval. $* *: p<0.01$ and $*: p<0.05$ as compared to vehicles. $\mathrm{C}$ : Effects of modafinil on CSD performance (interfering responses) at the 24 hours retention interval $*: \mathrm{p}<0.05$ as compared to vehicles.

Fig.5: Effects of modafinil on SSD performance at the 24 hours retention interval. No significant between groups difference was observed. Performance at D1 and D2 were measured on the same subject.

Fig. 6. A: Effects of stress on the dose-dependent modulation of D1 correct responses rates in stressed and non stressed vehicle or modafinil-treated mice; ***: $\mathrm{p}<0.001 ; *: \mathrm{p}<0.05$ as compared to the non stress condition; B: Effects of stress on the dose-dependent modulation of D1 interfering responses rates in stressed and non stressed vehicle or modafinil-treated mice; $* * *: p<0.001$ as compared to the non stress condition. C: Effects of stress on plasma corticosterone levels $(\mu \mathrm{g} / \mathrm{ml})$ in stressed and 
non-stressed vehicle or modafinil-treated mice; *: $p<0.05$. D: magnitude of the stressinduced corticosterone secretion in vehicle or modafinil-treated mice. *: $\mathrm{p}<0.05$; **: $\mathrm{p}<0.01$. 